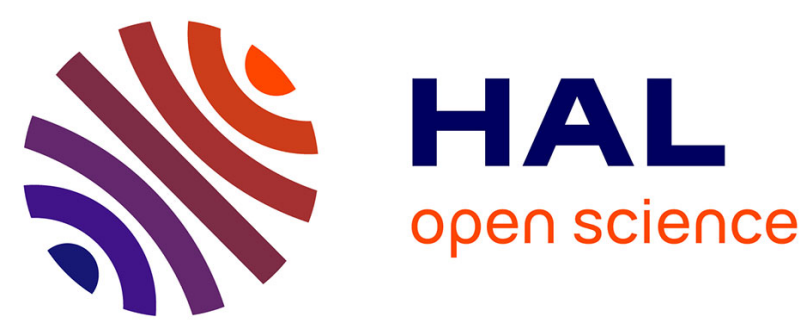

\title{
Broad-Band Measurement of all Complex Permeability Tensor Components and Complex Permittivity of Ferrites using a Rectangular Waveguide
}

\author{
Patrick Queffelec, Philippe Talbot, M. Le Floc'H, Ph. Gelin
}

\section{- To cite this version:}

Patrick Queffelec, Philippe Talbot, M. Le Floc'H, Ph. Gelin. Broad-Band Measurement of all Complex Permeability Tensor Components and Complex Permittivity of Ferrites using a Rectangular Waveguide. Journal de Physique IV Proceedings, 1997, 07 (C1), pp.C1-153-C1-154. 10.1051/jp4:1997154 . jpa-00255101

\section{HAL Id: jpa-00255101 https://hal.science/jpa-00255101}

Submitted on 1 Jan 1997

HAL is a multi-disciplinary open access archive for the deposit and dissemination of scientific research documents, whether they are published or not. The documents may come from teaching and research institutions in France or abroad, or from public or private research centers.
L'archive ouverte pluridisciplinaire HAL, est destinée au dépôt et à la diffusion de documents scientifiques de niveau recherche, publiés ou non, émanant des établissements d'enseignement et de recherche français ou étrangers, des laboratoires publics ou privés. 


\title{
Broad-Band Measurement of all Complex Permeability Tensor Components and Complex Permittivity of Ferrites using a Rectangular Waveguide
}

\author{
P. Queffélec, Ph. Talbot, M. Le Floc'h and Ph. Gelin \\ LEST-URA CNRS, 6 avenue Le Gorgeu, BP. 809, 29285 Brest cedex, France
}

\begin{abstract}
We have worked out a broad-band characterization method for magnetized ferrimagnetic materials. The technique is based on the reflection/transmission measurement of the S-parameters of a rectangular waveguide partly loaded with a ferrite that is to be characterized. The device is set in between the poles of an electromagnet to magnetize the sample. The fundamental principle of the measurement consists in using the anisotropy of the material to lead to the non-reciprocity of the cell $\left(S_{11} \neq S_{22}\right.$ and $\left.S_{21} \neq S_{12}\right)$ in order to have the same number of information that for the characteristics we want to determine (complex permittivity and all complex permeability tensor components). In this paper, we will compare in the X-band (8 $12.4 \mathrm{Ghz}$ ) the theoretical S-parameters of the cell with those measured by the network analyzer for different ferrites of wellknown properties in order to validate the electromagnetic analysis of the cell. We will underscore the importance of the losses which are entirely responsible for the non-reciprocity of the S-parameters modulus. To conclude we will suggest a strategy to resolve the inverse problem with an optimization method.
\end{abstract}

\section{INTRODUCTION}

In high frequency the implementation of signal processing functions (phase change, attenuation, insulation,...) requires the use of anisotropic ferrimagnetic substrates in the microwave circuits. The accurate control of the performance of such device calls for the achievement of broad-band electromagnetic characterization methods for constituent materials. Resonant methods (thus narrow-band) permitting the measurement of permittivity or permeability tensor components of anisotropic materials may exist but no broad-band measurement method has been developed until now as far as we know, except for diagonal tensor materials [1]. That is why we have worked out a broad-band characterization method for magnetized ferrimagnetic materials.

\section{DESCRIPTION OF THE DEVICE}

The configuration of the measurement cell is identical to the one used for the realization of non-reciprocal waveguide devices (insulators, commutation switches) except that there is no absorbing material in contact with the ferrite (fig.1). The advantages of the measurement cell are linked to the waveguide rectangular technology which is a well proven technology. This makes the use of specific calibration procedures for the network analyzer which are necessary for the achievement of precise measurements in high frequencies possible. Moreover the geometry of the cell is simple thus requiring little machining of the samples and makes the electromagnetic analysis of the cell easier. The condition of non-reciprocity of the cell has been proved by experimentation for different ferrites and values of the static field applied thus confirming the feasibility of the measurement technique.

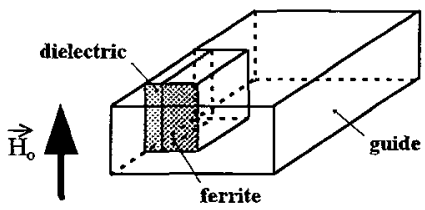

Fig. I : rectangular waveguide measurement cell.

A thorough electromagnetic analysis of a waveguide discontimuity consists in first, describing the electromagnetic situation (dispersion diagram, field patterns) on each side of the discontinuity and secondly to impose conditions at limits on the fields at the edge of the discontinuity. So the electromagnetic analysis of the measurement cell is made in two great parts. The first 
one is the determination of the modes in each region of the waveguide (empty region and region loaded with the ferrite). The second part consists in calculating the $S$ parameters of the cell according to the tensorial permeability which is written as follows :

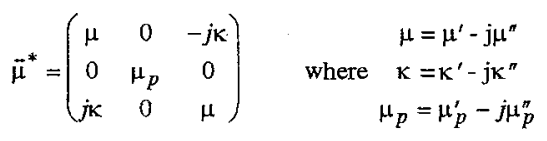

and to the scalar permittivity $\varepsilon^{*}$ of the ferrite present in the waveguide. The inverse problem that is to say determining $\vec{\mu}^{*}$ et $\varepsilon^{*}$ knowing the $S$ parameters of the cell measured in a high frequency band with a network analyzer remains to be done. But as the electromagnetic analysis of the cell is complex it is impossible to express analytically the components of the permeability tensor $\vec{\mu}^{*}$ and the scalar permittivity $\varepsilon^{*}$ according to the $S$ parameters of the cell. That is why the resolution of the inverse problem requires the use of numerical optimization methods. Before resolving the inverse problem the direct problem has to be validate especially in the real case that is to say for lossy ferrites.

\section{VALIDATION OF THE DIRECT PROBLEM}

The validation of the direct problem consists in verifying that the $S$ parameters calculated with the simulation software of the cell are in accordance with the ones measured in the cell loaded with a well-known ferrite in a broad frequency band. The permeability tensor components of a ferrite are no pure intrinsic parameters. For these components depend on the static field applied on the ferrite. So to compare the theoretical S parameters with the ones previously measured we will have to choose a model permitting us to calculate the permeability tensor components according to the static field applied during the measurement process and according to intrinsic parameters such as saturation magnetization given by the sample supplier. The model chosen is Polder's one [2].

A first series of theory/experimentation comparison has been done by neglecting ferrites losses in the calculations in order to simplify the research of solutions for the characteristic equation of the waveguide. From a theoretical point of view, in this case the non reciprocity of the cell could not be brought to the fore. Since then thanks to the creation of a new zero research procedure in the complex plane the real case (lossy ferrites) has been solved. In order to illustrate the experimental results we give in fig. 2.a the $\mathrm{S}$ parameters measured with the cell loaded with a well known ferrite (Ampex) of a saturation magnetization $M_{s}=5000$ Oe situated in a state field $H_{o}=1000 \mathrm{Oe}$. In the X band this ferrite is situated in a high lossy zone $\left(\gamma 4 \pi \mathrm{M}_{\mathrm{s}}=14 \mathrm{Ghz}\right)$. These measurements prove the non-reciprocity of the measurement device. We also notice that there is a good similarity between the measurements and the simulation shown in fig. 2 .b.

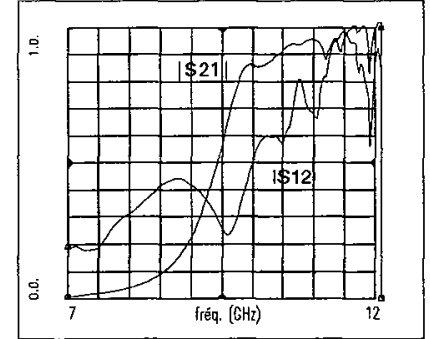

a) measurement $\left(H_{0}=1000 \mathrm{Oe}\right)$

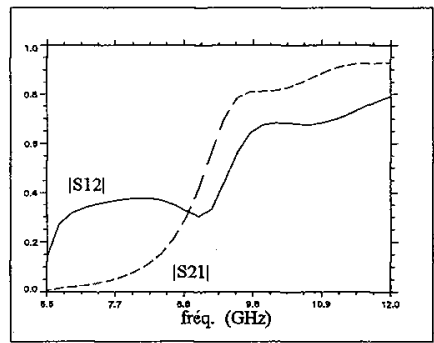

b) simulation $\left(\mathrm{H}_{i}=180 \mathrm{Oe}\right)$

Fig. 2: Modulus of the $S_{21}$ et $S_{12}$ parameters as function of frequency.

\section{CONCLUSION}

We have created a simulation software and realized a rectangular waveguide measurement cell in order to characterize anisotropic ferrites. The taking into account of losses in the calculations proved the non-reciprocity of the device confirming the feasibility of the measurement technique. Moreover the experimental results obtained have permitted to validate the direct problem in a broad frequency band. These encouraging results enable us now to consider the resolution of the inverse problem to study the electromagnetic characteristics of the anisotropic ferrites tested. But since many unknowns have to be determined ( 8 real parameters) the resolution will have to be done with caution to avoid the divergence of the calculations or the convergence towards local minima.

\section{References}

[1] N. E. Belhadj-Tahar and A. Fourrier-Lamer, "Broad-band simultaneous Measurement of the complex permittivity tensor for uniaxial materials using a coaxial discontinuity", IEEE Trans. on MTT, Vol. 39, №10, October 1991.

[2] Polder \& Smit, "Resonance phenomena in ferrites", Review of modern Physics, 25, pp 89-90, 1953. 